\title{
CRISIS Y RENOVACION DEL CONSERVATISMO CARTAGENERO
}

\author{
Luis Troncoso Ovalle *
}

En este artículo nos proponemos abordar el tema de la cultura política de la élite cartagenera durante el período de 1895 a 1905, empleando como fuente la prensa comercial de la época por su alto grado de politización, reflejo de la actitud política de la élite local en su mayoría conservadora, la que daba a este medio de información el carácter de instrumento de combate para difundir y defender su ideología y programas gubernamentales. La cultura política de las élites la definimos por contraste con la de los de abajo, pues si ésta tiene que ser reconstruida a partir de indicios y de acciones colectivas en las que difícilmente podemos distinguir a sus actores específicos, apareciendo como un pensamiento disgregado, el estudio de la cultura política de las élites se nos aparece más claro dado que sus luchas fracciónales siempre se daban por medio de actores en concreto, de voceros que expresaban de manera tácita sus reflexiones sobre los asuntos del Estado y de los partidos políticos. Por tanto, entendemos por cultura política las reflexiones que un grupo social o comunidad hace sobre los problemas del Estado, de la administración pública local o regional y sobre los partidos políticos ${ }^{1}$

Entendemos por élite, siguiendo a Peter Burke, a un grupo de personas que en determinadas circunstancias detentan en un contexto social específico

\footnotetext{
* Profesor del Programa de Historia, Universidad de Cartagena.

${ }^{1}$ Al respecto ver: BURKE, Peter. La Cultura popular en la Europa Moderna. Madrid, Alianza Ed., 1991 (especialmente el aparte "Politización de la cultura popular"). También ver a: GARRIDO, Margarita. Reclamos y representaciones. Santafé de Bogotá, Banco de la República, 1993, y sobre las diferencias entre las culturas políticas de los de abajo y los de arriba ver: SEWELL, William jr. Trabajo y Revolución en Francia. El Lenguaje del movimiento obrero desde el antiguo Régimen hasta 1848. Madrid, Taurus Eds., 1992.
} 
poder, riqueza y rango, entendidas cada una como cierta exclusividad con relación al resto de la sociedad. Según este autor, estos factores no siempre se aplican uniformemente a un mismo grupo, pues es posible tener uno, dos o el total de ellos. En determinadas circunstancias un grupo o sector de éste puede detentar poder (político, de conocimiento, de técnica, de fuerza, ascendencia sobre sectores de la población que se podían movilizar a "voluntad"), pero puede estar excluido de riqueza y de rango social; o a la inversa, puede tenerse riqueza mas no poder y puede disfrutarse de rango, pero estar excluido de las otros dos categorías ${ }^{2}$. Creemos que en el caso de Cartagena los tres factores usualmente se combinaban en un mismo grupo de personas, en especial con los usufructuarios de la hegemonía conservadora, por lo que rango, poder y riqueza les permitía influir en la acción histórica de una colectividad, ya sea por las decisiones que toman, ya por las ideas, los sentimientos o las emociones que expresan o simbolizan. Estas élites protagonizaban hechos como: debates políticos a través de la prensa frente a hechos de trascendencia nacional, los pronunciamientos que en nombre de cada uno de los partidos tradicionales o sus fracciones coyunturales se hacían acerca de cualquier acontecimiento del devenir político nacional; las campañas que desde la localidad se adelantaban para reivindicar la categoría político-administrativa de la ciudad o el departamento; las acciones y reacciones alrededor de la gestión administrativa o legislativa del Estado en sus instancias nacional y local; los constantes debates ideológicos que en los editoriales de prensa se desarrollaban referente al quehacer de sus partidos y sus programas ${ }^{3}$.

Con el fin de aclarar algunos aspectos de la política conservadora traeremos a colación elementos de la política liberal pues al fin y al cabo una siempre se define en función de la otra.

2 BURKE, Peter. Venecia y Amsterdam. Estudio sobre las élites del siglo XVII. Barcelona, Gedisa, Ed, 1996.

3 ÁLVAREZ LLANOS, Jaime. "La cultura política de las élites locales en el Atlántico a principios del siglo XX", en: Historia y Pensamiento. Barranquilla, Universidad del Atlántico, 1997. N 1, p. 7. 


\section{CARTAGENA A LA VUELTA DE SIGLO}

Durante la administración Núñez en el Estado Soberano de Bolívar, desde 1877 y la primera presidencia nacional en 1882 , se dio un nuevo impulso a la vida económica de la ciudad; la reapertura del Canal del Dique, la preocupación por la agricultura y la ganadería que venían generando un auge comercial desde 1870, el resurgimiento de la minería, la creación de establecimientos semifabriles y fábricas, la fundación de los primeros bancos y la posterior construcción del ferrocarril Cartagena-Calamar (1892) fueron los primeros resultados, los que en gran parte respondieron al interés y la preocupación de Núñez por generar "un modelo alternativo que tuviera como epicentro la economía urbana"

A pesar de estas medidas, el fracaso de las políticas de la Regeneración engendraron una crisis; la caída de los precios internacionales del café, producto cuyo primer auge coincidió con el ascenso de la Regeneración al poder, el acentuamiento de la política de intolerancia gubernamental, el proceso inflacionario que originó las emisiones de papel moneda del Banco Nacional y el surgimiento de una generación de jóvenes liberales que se manifestaban en pro de ir a la guerra civil para llegar al poder, aceleraron el conflicto bélico 5 .

Una vez terminada la guerra la situación económica nacional y local era desastrosa. Muchas casas comerciales cerraron sus puertas, quienes se dedicaron a acumular papel moneda quebraron cuando el gobierno de Marroquín realizó la reconversión monetaria, los primeros ensayos fabriles también se afectaron. También la estructura urbana de la ciudad manifestó cierto estancamiento con relación al proceso de reconstrucción que se venía dando desde finales del siglo XIX, gracias a la exoneración de impuestos que había decretado el Concejo Municipal para las personas o empresas que reconstruyeran las edificaciones.

\footnotetext{
${ }^{4}$ SOLANO, Sergio. "Trabajo y Ocio en el Caribe Colombiano (1880-1930)" en: Historiay Cultura. Cartagena, Universidad de Cartagena, 1996. Ns4. 1996, p. 63

${ }^{5}$ BERGQUIST, Charles. Café y conflicto en Colombia. Medellín, Faes, 1984, p. 119.
} 
Las arcas oficiales, tanto del municipio como del departamento, también denotaban la crisis económica, de tal manera que en 1899 Lácides Segovia, encargado de la Secretaría de Hacienda por el gobernador Ricardo Núñez, se quejaba del estado de ruina en que se encontraba el tesoro seccional por obra de las: "contiendas armadas, por negligencia de sus funcionarios y también por deplorable aflojamiento de los resortes cívicos de los bolivarenses. En la provincia de Barranquilla primaba un espíritu de cooperación y de progreso mucho más pronunciado, por esta causa los recaudos que ahí se obtenían eran proporcionalmente mayores que los atesorados por el resto del departamento"6.

Sm embargo, muchos empresarios supieron aprovechar el conflicto bélico y la crisis financiera que le precedió, para enriquecerse por múltiples vías. Durante la guerra la saca clandestina de ganado en pie rumbo al extranjero y a Antioquia, que no fue escenario del conflicto bélico, continuó, pues la guerra no afectó a todos los rincones del agro costeño, algunos en vez de acumular papel moneda lo hicieron en oro y cuando llegó la reconversión monetaria se vieron favorecidos por esta medida; el contrabando continuó campeando en muchas ensenadas y radas de la costa, especialmente de productos alimenticios escasos durante la guerra con los que se dedicaron a especular; otros prestaban dinero con altas tasas de interés lo que les permitió hacerse a las viviendas y tierras de sus deudores, etc. Lo cierto es que una vez finalizada la guerra, Cartagena y el resto del departamento de Bolívar vio surgir un sector empresarial "emergente". Fueron estas fortunas, muchas de ellas provenientes de las sabanas de Bolívar y de la región del Sinú (Martínez Camargo, Vélez Racero, Burgos, Cabrales, Goméz Padrón, Gómez Pernett, Hoyos, Támara y muchos otros) las que después de la guerra se trasladaron a Cartagena gracias al protagonismo político que comenzaron a desplegar sus poseedores, las que iniciaron el proceso de despegue económico de esta ciudad durante buena parte del siglo XX.

Antes de posesionarse el General Reyes, en Cartagena ya empezaba a vislumbrarse una nueva etapa de progreso y prosperidad traducida en la

6 AGUILERA, Miguel. Lalides Segovia. Ed ABC. Bogotá, 1959, p. 31. 
construcción de ciertas obras y la llegada de algunos servicios públicos que le imprimían a la ciudad un aspecto de renovación.

\section{CARTAGENA Y LA GUERRA DE LOS MIL DÍAS}

Aunque Cartagena no fue escenario de acciones bélicas, como sí sucedió en 1885, la impreparación con que se cogió a los liberales de la ciudad la apertura de hostilidades por parte de los pronunciamientos de Santander y Barranquilla, y al estar avisadas las autoridades, obligaron a muchos de aquellos a tener que quedarse en la ciudad ante el cierre de las puertas y la vigilancia extrema que se puso en todos los baluartes y cortinas de las murallas. Presidio y fianzas tuvieron que pagar para poder mantener cierta libertad de movimiento dentro de la ciudad y ello terminó por ser un factor de perturbación constante del orden público.

En las inmediaciones de la ciudad se presentaron incursiones de las guerrillas liberales, como también en poblaciones vecinas como Mahates, Luruaco, Arenal, Arjona, Turbaco, San Estanislao y Villanueva ${ }^{7}$. La ciudad también fue escenario de esporádicos disturbios ocasionados por los liberales, lo que obligó a Joaquín F. Vélez, jefe civil y militar de la plaza, a tomar fuertes medidas contra la población liberal de la ciudad ${ }^{8}$.

También se les prohibió a los liberales, la venta de ganado a extranjeros y nacionales, pues lo estaban negociando para eludir el pago de las contribuciones de guerra que en su condición de enemigos del gobierno se les imponía 9 . El liberalismo también fue atacado desde la prensa conservadora, la que dedicó gran parte de su espacio para desacreditarlo; en 1902 son constantes las rectificaciones y protestas por parte de liberales que se pasaban al partido de gobierno, las que eran aprovechadas en beneficio del conservatismo.

7 El Porvenir. Cartagena, febrero 23 y mayo 2 de 1902.

8 Decreto N 184 sobre Orden Público. El Porvenir. Cartagena, febrero 5 de 1902.

9 Decreto $\mathrm{N}^{\circ}$ 283. El Porvenir. Cartagena, 14 de marzo de 1902. 
Otro punto al que se aferraban los conservadores para criticar al liberalismo, era la utilización repetida de métodos violentos para competir por el poder, lanzándose a la guerra cada vez que no podían vencer a su contendor mediante un debate "civilizado", llevando al país a la ruina cada vez que se alzaban en armas. Pero si se aludía la culpabilidad de los desórdenes por parte de la masa liberal, dentro de los sectores conservadores también se presentaron graves disturbios por algunos roces entre civiles conservadores y militares activos del ejército nacional que causaron gran estupor e indignación en la ciudad ${ }^{10}$.

También el clero cartagenero representado por Monseñor Pedro Adán Bnoschi, personaje que jugó un papel determinante en la vida política y social de Cartagena durante el último período finisecular, y al cual Lemaitre describe "como un hombre virtuoso, caritativo, ilustrado y de carácter autoritario y recio, con una visión del mundo ajena a los nuevos tiempos"11. Brioschi, dirigió pastorales que se hicieron famosas en toda la ciudad por el carácter que les imprimía en pos de la defensa de un catolicismo ultramontano, manifestándose en contra de las prácticas y las doctrinas liberales las que consideraba como fruto de la ignorancia del catecismo.

\section{EL IMPACTO DE LA GUERRA DE LOS MLL DÍAS EN LA POLÍTICA B OLI VARENSE}

La Guerra de los Tres Años (1899-1902) alcanzó una gran significación por sus consecuencias en algunos aspectos de la cultura política regional y nacional. Este impacto se manifestó en el campo de la cultura política liberal costeña, pues alrededor de sus remembranzas, tanto de los episodios bélicos como de sus actores y de sus motivos ideológicos, se restructuró parte del pensamiento liberal regional, renaciendo una especie de doctrinarismo liberal que había pasado a un segundo plano entre 1886 y 1899.

\footnotetext{
${ }^{10}$ Horrendo Crimen. El Porvenir. Cartagena 31 agosto 31 de 1902.

${ }^{11}$ LEMAITRE, Eduardo. Historia General de Cartagena. Banco de la República, Bogotá, 1983, Tomo IV, pág. 505.
} 
El conservatismo como partido triunfante, aunque pretendió borrar el recuerdo de la guerra, lo que se refleja en el hecho de que todas las memorias escritas y publicadas en la Costa por los combatientes fuesen realizadas por liberales ${ }^{12}$, no pudo sustraerse a sus consecuencias, profundizándose su división, lo que a la vez obligó a algunas de sus fracciones (nacionalistas o históricas) a acudir a alianzas con algunos sectores liberales para poder mantenerse en el poder. En gran medida, y reflejando el pensamiento de algunos conservadores del interior del país, los conservadores costeños también presentaron la acción de los ejércitos legitimistas como una especie de "Santa Cruzada" para defender a la Iglesia católica y a las tradiciones amenazadas por un enemigo exterior, el

12 Algunas de estas memorias son: ACOSTA, Aureliano. Memorias de un sobreviviente del glorioso liberalismo colombiano. Bogotá, Ed. Cromos, 1940; BERDUGO, Juan. Memorias de la Guerra de los Mil Días escritas por el General Juan Berdugo, en: Estudios sociales. Medellín, Fundación Antioqueña para los Estudios Sociales, 1995. Nos. 8-9, BERNIER, Agustín. Datos sobre el territorio guajiro. Riohacha, Imp. La Frontera, 1911; DURAN, Justo L. La Revolución del 99. Bogotá, Talleres Tip. El Día, 1920; FRANCO, Pedro A. Mis andanzas en la Guerra de los Mil Días: Acciones en el departamento del Bolívar. Barranquilla, Imp. Departamental, 1964; GARCÍA MAYORCA, Carlos. La Batalla de Ciénaga. Santa Marta, Tip. Mora y Escofet, 1951; GÓMEZ, Octavio M. La Guerra de los Mil Días. El combate de Carashua. Santa Marta, Imp. El Estado, 1947. [Aparece inserto en la obra de J.M. Valdeblánquez]; LUNA CÁRDENAS, Alberto. Un año y otros días con el general Benjamín Herrera en las bananeras y Aracataca. Medellín, Ed. Bedout, 1970; MENDOZA MENDOZA, Manuel. Leyendas Sinuanas. Cereté, Ed. Sinú, 1949; NO-RIEGA, Manuel A. Recuerdos históricos de mis campañas en Colombia y el Istmo 1876-1902. Panamá, Tip. Moderna, 1927; PÉREZPRASCA, Samuel. La Batalla de Juan Gordo, s.p.i., 1986; PINEDA C, Manuel Antonio. Efemérides de la Campaña del general Rafael Uribe Uribe en Bolívar. Cartagena, Ed. Bolívar, 1939, PORRAS, Belisario. Memorias de las campañas en el istmo, 1900. Panamá, Imp. Nacional, 1922; REDONDO MENDOZA, Rafael. Daguerrotipos Liberales. Cartagena, Imp. Departamental, 1936; ROBLES, Juan Lázaro. Recuerdo de la Guerra de los Mil Días en las provincias de Padilla y Valledupar y en la Guajira. Santa Marta, Tip. Escofet, 1946; ROSA, Domingo de la. Recuerdo de la Guerra de los Mil Días 1899-1902 (Cauca y Panamá). Barranquilla, Imp. Departamental, 1938; SIERRA BARÓN, Ramón. Episodios gloriosos de una campaña. Sincelejo, Talleres de "Correo de Sabanas", 1942; SOCARRAS, Sabas. Recuerdo de la Guerra de los Mil Días. Bogotá, Ed. Tercer Mundo, 1977; TOVAR MOZO, Efraín. Zig zag en las Bananeras. Bogotá, Ofset de Colombia, 1964; URIBE URIBE, Rafael y URUETA, Carlos Adolfo. Documentos políticos y militares. Medellín, Beneficiencia de Antioquia, 1982. Tomo IV. VESGA Y ÁVILA, José M. La guerra de tres años. Bogotá, Imp. Eléctrica, 1914; ZARANTE, José Dolores. Reminiscencias historias (Recuerdos de un soldado militar). Cartagena, Imp. Departamental, 1933. Sólo conocemos cuatro obras escritas por conservadores en los que se hace referencia a la guerra en la Costa: SALAZAR, Víctor Manuel. Memorias de la Guerra (1899-1902). Bogotá, Ed. ABC, 1943 y VALDEBLÁNQUEZ, José María. Historia del Departamento del Magdalena y del territorio de la Guajira desde el año de 1895 hasta el de 1963. Bogotá, El Voto Nacional, 1963 (conservador), de este autor Véase: Biografía del general Florentino Manjarrés. s.p.i. y AGUILERA, Miguel. Lacides Segovia. Un carácter. Bogotá, Ed. ABC, 1949. 
liberalismo, la masonería y el racionalismo. Aunque durante el período del Quinquenio esta idea pasó a un segundo plano dado la alianza momentánea entre los conservadores nacionalistas y el liberalismo uribista, una vez caído Reyes en 1909 y la posterior crisis del Republicanismo en 1911, conllevó a que se reviviera dada la necesidad de delimitar las fronteras con el liberalismo y la masonería, echando mano de muchos recursos ideológicos que se habían esgrimido durante la guerra ${ }^{13}$. Esas ideas fueron defendidas en el medio regional bolivarense por sus seguidores incondicionales, como Abel Mariano Irisarri, Manuel Pájaro Herrera y Luis Patrón Rosano, quienes ejercían una especie de hegemonía académica oficial en la Universidad de Cartagena, e intentaron formar a las jóvenes generaciones de intelectuales bajo esos preceptos.

Otra secuela significativa de la Guerra de los Mil Días fue la renovación de las direcciones de los partidos. De una parte emergió una nueva generación de dirigentes liberales, que se encargó de reorientar las estrategias del partido para poder enfrentar las nuevas realidades que trajo el siglo XX, a la vez que se construía un nuevo panteón de héroes y nuevos mitos y leyendas, que alimentaron buena parte de la cultura política popular. El conservatismo también vio florecer una nueva generación de dirigentes, la que presentó algunas novedades como la de ser algunos de ellos oriundos de las provincias de las sabanas de Bolívar, quienes llegaron a ocupar cargos de significativa importancia tanto en ese partido como en los político-administrativos del departamento de Bolívar y el municipio de Cartagena. Otro rasgo de estos nuevos dirigentes fue que aunque conservaron muchos de los viejos aspectos del estilo caudillista, de alguna manera se aproximaron al líder carismático moderno.

Esta emersión de nuevas direcciones políticas a escala regional a partir de la Guerra de los Mil Días y del nuevo siglo, significó que en determinadas circunstancias y en algunos territorios de la región la guerra estimuló procesos de movilidad política y social de personas de diversos grupos sociales y provenientes de otras comarcas, quienes lograron desarrollar

13 Ver: DÁVILAF., Manuel. Catolicismo y protestantismo comparado de manera epistolar. Roma, Tip. Salesiana, 1924. 
novedosos protagonismos políticos. Esto se comprende de mejor manera si observamos que en los períodos de paz la vida política y social mantenía una jerarquía social y política determinada por la riqueza, el control del poder y el rango social e intelectual, posibilitando que personas de diversas extracciones sociales relacionadas por ser militantes de un mismo partido se aproximaran, pero dentro de una rígida estructura del caciquismo, clientelismo y caudillismo.

En el caso del conservatismo, al ser el partido de gobierno que tenía a su disposición una estructura militar organizada, jerarquizada y ordenada, fue difícil que sobresalieran personajes por la sola acción militar dado que el combate disciplinado conllevaba a que los palmarás de los triunfos se los llevaran las altas jerarquías militares, confundidas éstas con personalidades de la vida social, económica y política de la región. Entre la población conservadora se volvieron proverbiales las acciones de los generales Juan B. Aycardi (parte de una familia empresarial y emparentado con Bartolomé Martínez Bossio), Luis Vélez Racero (empresario y sobrino de Joaquín F. Vélez), Francisco Burgos Rubio (hacendado del Sinú), Miguel Torralvo (hacendado sinuano), Francisco de J. Palacio (empresario barranquillero y primo de Rafael Núñez), Diego A. de Castro (empresario barranquillero) y muchos más. Por tanto la acción militar en este caso no generó movilidad política, en el sentido anotado para el caso de los liberales.

Empero, aquellas personas pudientes de las comarcas que basadas en sus ascendencias sociales lograron movilizar a gruesos sectores de la población en apoyo a la causa de la legitimidad, sí lograron hacer de esta solidaridad con el gobierno un mecanismo de reconocimiento político, como fue el caso de muchos hacendados de las sabanas y del Sinú. Este reconocimiento político coronaba los nexos que se establecieron entre el empresariado cartagenero y los hacendados sabaneros desde el último cuarto del siglo XIX, de lo que son una prueba los vínculos de los Vélez Daníes con los Martínez Camargo, Vélez Racero, Burgos, Cabrales, Gómez Pernett, Vellojín y otras familias hacendatarias de las sabanas ${ }^{14}$.

14 Algunos de esos vínculos pueden estudiarse en: BURGOS PUCHE, Remberto. El general Burgos. Bogotá, Ed. ABC, 1964; RESTREPO, Jorge y RODRÍGUEZ, Manuel. "La actividad comercial y el grupo de comerciantes de Cartagena a finales del siglo XIX", en: Estudios sociales. Medellín, Faes, 


\section{CAMBIOS EN LA CULTURA POLÍTICA: DE LO REGIONAL A LO NACIONAL}

Además de la movilidad política que propició la Guerra de los Tres Años, también estimuló el desarrollo de una mentalidad civilista en ambos partidos, la que se venía anunciando desde finales del siglo XIX. Esta mentalidad se reflejó en el abandono por parte del liberalismo de cualquier pretensión de llegar al poder por vía de las armas, su reconocimiento a la legalidad que había establecido la Constitución de 1886 y su decisión de lograr reformas políticas que le garantizaran un mayor espacio político para sus actividades. Quizá la mejor expresión de este cambio a nivel regional fue Francisco de P. Manotas Hernández, liberal radical sabana-larguero con gran ascendencia política en Bolívar ${ }^{15}$.

Esta reorientación liberal tuvo su contrapartida entre los dirigentes conservadores, quienes gracias al experimento que se hizo durante el Quinquenio, cuando el sector liberal dirigido por Uribe U. participó en el gobierno, abandonaron hasta cierto punto las desconfianzas que les inspiraban los liberales y desarrollaron políticas de alianzas. Es posible pensar que el ethos cultural costeño haya influido en que se facilitara las convivencias partidistas en Bolívar tal como afirma Fals Borda a propósito de Juan José Nieto. Además, téngase presente que los principales epicentros urbanos de la región eran pequeñas poblaciones (en 1905 Cartagena y Barranquilla contaban con 14.000 y 40.115 habitantes respectivamente), lo que determinaba proximidades sociales y culturales por encima de las rencillas partidistas. Códigos de honor y caballerosidad practicados durante las contiendas civiles y en la cotidianidad entre los dirigentes de ambos

1986. N ${ }^{\circ}$ 1; POSADA CARBO, Eduardo. El Caribe colombiano. Una historia regional 1870-1950. Santafé de Bogotá, Coed Banco de la República-El Áncora Eds., 1998; RIPOLL, María T. "El Central Colombia. Inicios de industrialización en el Caribe colombiano”, en: Boletín Cultural y Bibliográfico. Santafé de Bogotá, Biblioteca Luis Ángel Arango, 1997. N 45; MACHADO AMADOR, Alberto. La exportación de carnes y el Packing House de Coveñas 1918-1938. Cartagena, Corporación Tecnológica de Bolívar, 1989. (Tesis para optar título de economista).

15 La entrevista con el Doctor F. de P Manotas. El Porvenir. Cartagena, febrero 17 de 1904. 
partidos, lo que sumado a expresiones culturales como las festividades y un fuerte sentido de pertenencia regional los acercaban.

En el fondo de estos cambios en el conservatismo estaban algunas transformaciones que se escenificaron en la política nacional desde la Regeneración en adelante. Una de esas transformaciones fue que el pensamiento político de los dirigentes conservadores bolivarenses comenzó a trascender los límites de las preocupaciones regionales para tener como punto de reflexión los problemas nacionales, lo que en parte se debió al hecho de que Núñez abrió las puertas del Estado central a los costeños (José Manuel Goenaga, Felipe Angulo, Diniosio H. Araújo, Benjamín Noguera, Joaquín F. Vélez, Benjamín Baena, Nicanor Insignares S., José M. Campo Serrano, Rufo Urueta y otros llegaron a ocupar ministerios durante la Regeneración).

Esto permitió que las preocupaciones de los políticos conservadores costeños más prominentes se centraran en problemas nacionales, colocándose por encima de los problemas y las disecciones regionales y locales, las que en parte quedaron relegadas a los políticos de estos ámbitos, desempeñando muchas veces papeles de árbitros. Cuando señalamos que son preocupaciones políticas nacionales, más que decirlo por su presencia en toda la geografía nacional como lo describe M. Deas, señalamos el hecho de que los políticos costeños establecieron contactos y relaciones con políticos de otras regiones que hasta cierto punto homogenizan sus pensamientos relacionados con los problemas del Estado, de la educación y de la religión. En un estudio reciente se afirma que durante la regeneración "Hubo política nacional y articulación de intereses sin clase dominante hegemónica en el sentido burgués", y se describen los elementos nacionales de esa política a través de caudillos cuyos poderes sobrepasan los linderos de sus regiones, poderes que se ejercen en el marco de unas instituciones públicas más o menos homogéneas en todo el territorio nacional, burocracia, códigos, régimen tributario, ejércitos que se movilizan en diferentes espacios regionales, religión única, una historia percibida como común y rituales y símbolos partidistas y patriotas. Agrega que pese a las diferencias partidistas los sectores dominantes se reconocían como 
partícipes de un mismo destino, lo que define una especie de conciencia protonacional. Para Posada Carbó, esta ligazón entre la política local y regional y la nacional en gran medida se debió a la centralización del Estado a partir de 1886, proceso que se profundizó con el pasar de los años, muy a pesar de las resistencias que se opusieron desde diferentes frentes regionales ${ }^{16}$.

Efectivamente, sólo afínales del siglo XIX asistimos a la integración de la clase dominante, tanto a nivel regional como nacional, de lo que es muestra el ámbito de las operaciones económicas de los empresarios que ya sobrepasan las fronteras de sus regiones (como fue el caso de Juan B. Mainero y Trueco), lo que también tiene validez para las esferas de sus acciones políticas, integración que se reforzó a la vuelta de siglo bajo el Quinquenio de Rafael Reyes y la Unión Republicana. Las preocupaciones de esta clase dominante nacional en formación se centraron más en lo nacional que en lo regional, aunque los conflictos que ella vive se deben, situación paradójica, a la intervención de lo nacional en las esferas de sus actividades regionales. Es, sin lugar a dudas, un sector social que está transitando de lo regional a lo nacional.

Este tránsito, más que hallar su explicación en el área de sus inversiones (al fin y al cabo, para el caso costeño al ejemplo de Mainero y Trueco sólo se sumó el de José Vicente Mogollón a comienzos del siglo XX, pues el primero retrotrajo sus inversiones al espacio de la provincia de Cartagena), se debió a las exigencias del proyecto regenerador, el que definió la integración política ya no sólo con base en los caudillos (los que no dejaron de existir), sino en una práctica política más orgánica, más partidista, más burocrática y ligada a un nuevo tipo de Estado. R. Núñez representa para el caso costeño, al igual que José M. Campo Serrano, José Manuel Goenaga, J. F. Vélez, José F. Insignares Sierra, M. Dávila Flórez, Felipe Angulo, Benjamín Noguera, Lácides Segovia, Henrique L. Román y otros, el tránsito del vínculo caudillista (representado en el período liberal radical por Juan José Nieto, Manuel y Antonio González Carazo, Santo Domingo 
Vila o durante los años de 1840 por Francisco Carmona) al vínculo partidista, definido por una relación directa con los asuntos del Estado. Durante el liberalismo radical fue difícil que en Bolívar se estabilizara, con la sóla excepción de J. J. Nieto, la hegemonía política de una sola persona durante largo tiempo; además la precariedad de la burocracia estatal contrarrestaba que se hiciera del Estado una fuente duradera de poder.

Después de la Regeneración, la práctica política orgánica, partidista y burocrática estaba definida por la naturaleza del proceso centralizador del Estado y su no diferenciación con el partido que ejercía la hegemonía política; todo acto administrativo de índole local o regional debía remitirse al gobierno nacional, fuente de consulta para aclarar o asumir determinaciones. Es el inicio del triunfo del poder central sobre el regional, lo que se reproducía en estas esferas con la preeminencia de los representantes del poder ejecutivo (alcaldes y gobernadores) sobre los organismos legislativos. Ahora, cualquier determinación local o regional requería del conocimiento de la política y del funcionamiento de las instituciones nacionales, lo que en últimas coadyuvó a la nacionalización de la política. Esta forma de ejercitar la política definió nuevas lealtades en el marco del partido de gobierno y de la burocracia de turno.

\section{EMPRESARIOS POLÍTICOS: CAMBIOS A LA VUELTA DE SIGLO}

Vanos hechos sobresalen en el estudio de los comportamientos y adscripciones políticas de la élite cartagenera durante el período que analizamos. El primero de ellos es que en el contexto regional la vida política de la élite cartagenera del último período finisecular acusa ciertas particularidades si se le compara con la de Barranquilla: mientras que ella fue mayoritariamente conservadora, la dirección del liberalismo, con contadas excepciones, estuvo en manos de profesionales de extracción media o humilde, como fueron los casos de Juan A. Fortich, Eloy Pareja G, Simón Bossa Pereira, Antonio Regino Blanco, Alejandro Amador y Cortés, Miguel Gómez Fernández, Miguel Díaz Granados, Manuel A. Núñez Ripoll. Aquellos liberales pudientes que habían tenido cierto protagonismo político durante los decenios de 1860 a 1880, pasaron, a 
través del liberalismo independiente, a engrosar las filas del Partido Nacional y luego terminaron militando en el conservatismo (Benjamín Baena, Benjamín Noguera, F. Angulo, A. Araújo de L. y muchos más).

Esa inclinación de la élite cartagenera hacia el conservatismo, que podemos vislumbrar desde el tercer cuarto del siglo XIX con los Vélez, Zubiría, Maciá, del Castillo, Román, Grau, Pombo, etc. ${ }^{17}$, se profundizó con el ascenso de la Regeneración al poder en la década de 1880, cuando Núñez y sus seguidores abrieron un espacio político para que un emergente sector empresarial participara activamente en política local y regional. Es durante esos años que personajes como Bartolomé Martínez Bossio, Henrique L. Román, José María de la Vega Vélez, Carlos Vélez Daníes y otros, comenzaron a descollar en la dirección pública de la ciudad y de la región, grupo que se reforzó con el traslado a la capital del departamento de Bolívar de muchos empresarios de las sabanas como los Burgos, Martínez Camargo, Vélez Racero, Gómez Pernet, etc., y con los liberales conversos al conservatismo.

Este reforzamiento con patricios de las provincias, en buena medida se debió a que al extender la élite cartagenera sus operaciones empresariales hacia las sabanas de Bolívar, el Sinú y el Atrato, abrió las puertas para que empresarios comerciales y ganaderos de esas comarcas se vincularan a la vida político-administrativa del departamento de Bolívar, desarrollando intensas formas de lealtades políticas, devenidas de los vínculos empresariales y de las relaciones matrimoniales. Una segunda característica de la élite conservadora es que sus comportamientos políticos variaron acorde con ciertas identidades generacionales y con sus vínculos con las principales actividades económicas de la región. En efecto, quienes ejercieron la hegemonía política en Bolívar durante la regeneración fueron personajes nacidos en la segunda mitad del siglo XIX (casi todos en el decenio de 1850 con excepción de J. F. Vélez, R. Núñez, B. Baena, M. Vives O. y otros personajes secundarios), algunos de extracción elitista y

17 Ver: SOLANO, Sergio. "Empresarios, proyectos de modernización e imaginarios sociales en la provincia de Cartagena durante la primera mitad del siglo XIX". Historia y Cultura. Cartagena, Universidad de Cartagena, 1995. N 3. 
otros no, muchos de los que hicieron carrera política desempeñando, paso a paso, la jerarquía de los cargos públicos, hasta llegar a los ministerios. Casi todos ellos estuvieron bajo las sombras de Núñez y de J. F. Vélez, los más connotados representantes del bipartidismo regional costeño durante el último cuarto del siglo XIX. Manuel Dávila Flórez nació en 1851, José María Pasos en 1858, Luis Patrón Rossano en 1854, Eduardo Gutiérrez de Piñeres en 1853, Carmelo Arango en 1854, Pedro Vélez Racero en 1859, Henrique L. Román Polanco en 1851, José María de la Vega Vélez en 1854, Carlos Vellojín Burgos en 1859, Emilio T. de Hoyos en 1850, Lácides Segovia en 1854, Manuel Pájaro Herrera en 1854, Antonio Araújo de León en 1852, Gabriel E. O'Byrne Carrillo en 1858, Felipe Angulo Bustillo en 1854. En su juventud casi todos compartieron las aulas del Colegio del Estado (Universidad de Cartagena) y del Colegio de La Esperanza, e hicieron sus primeras incursiones en política finalizando los años de 1870, cuando el nuñismo, agrupado en la fracción liberal independiente, dominaba en el Estado de Bolívar. Por tanto, su toma de partido estuvo enmarcada en la crisis del radicalismo y en el reactivamiento de la economía cartagenera impulsado por el liberalismo independiente, lo que en líneas gruesas explicaría sus adscripciones al movimiento regenerador ${ }^{18}$.

Las fuentes de poder de estos personajes fueron variadas, como también lo eran sus lugares de origen. M. Dávila F., momposino, vivió toda su vida de la política; E. Gutiérrez de $\mathrm{P}_{7}$ también oriundo de la Ciudad Valerosa, fue un conotado institutor y escritor; los hermanos Luis y Pedro Vélez Racero provenían de una familia empresarial y hacendataria; L. Segovia toda su vida vivió de la política y de pequeños negocios que estableció en las postrimerías de su existencia; Ramón P. de Hoyos, Carlos Vellojín y L. eran hacendados monterianos; Luis Patrón Rosano, oriundo de Tolú-viejo, era hijo de un mediano terrateniente pero sobresalió por su dedicación a la docencia y por el desempeño de cargos públicos a los que era llamado por

18 Ver: RESTREPO, Pastor. Genealogía de Cartagena de Indias. Santafé de Bogotá, Instituto Colombiano de Cultura Hispánica, 1994; en algunos ejemplares del Boletín Historial de la Academia de Historia de Cartagena aparecen semblanzas biográficas de algunos de estos personajes; también ver: VEGA, Fernando de la. Cartagena la de los claros varones. Cartagena, Ed. El Mercurio, 1936. 
su probidad y honradez; E Angulo Bustillo, sanjuanero, era hijo de un profesor y comerciante mediano con tabaco en la época en que esta hoja floreció en la comarca de El Carmen, y los demás mencionados eran nativos de Cartagena, con niveles de fortuna muy desiguales (sobresaliendo los empresarios Araújo y Román, dedicado el primero al periodismo y el segundo a negocios muy diversos).

La mayoría de ellos halló en el estudio de profesiones liberales (abogados y médicos), en el escalamiento peldaño por peldaño en cargos de la administración pública y en los vínculos con personajes influyentes (con Núñez y J. F. Vélez), el apoyo suficiente para desarrollar brillantes carreras políticas, en la época en que Cartagena, a pesar de su decadencia material, continuaba siendo el epicentro de la política y de la educación universitaria regional. Una buena razón de ello es que el ejercicio de cargos en la administración pública requería de personas con algún grado de preparación, al tiempo que era poco remunerada, por lo que jóvenes recién egresados de las aulas de los planteles de educación superior comenzaban a temprana edad la carrera política, mal vista durante mucho tiempo por los empresarios quienes veían en ella un motivo de alejamiento de sus negocios. La época en que nacieron, irremediablemente les obligó a vivir en sus años juveniles y de madurez las postrimerías del dominio del liberalismo radical y algunas de las guerras civiles escenificadas en esos años, por lo que algunos vivieron un proceso de desencantamiento con relación al liberalismo y se deslizaron hacia el conservatismo. Además, presenciaron el ascenso de la carrera política de R. Núñez, y vieron con orgullo cómo un hijo de Cartagena ascendía y ocupaba los más altos cargos de la vida político-administrativa nacional, lo que reforzó mucho más sus proclividades hacia el conservatismo.

En contraste con esta generación de los años cincuenta, quienes nacieron en los años de 1860, como fueron los casos de Carlos Vélez D. en 1860 y su hermano Fernando en 1862, Francisco Burgos R. en $1865^{19}$, Diego

19 Su padre, el abogado Manuel Burgos, graduado en la Universidad de Cartagena en 1845, electo por el liberalismo a la Cámara Provincial de Cartagena en 1849, luego asistió a la Cámara de Representantes en 1850, y después, en 1856, cuando la candidatura de M. Ospina R., engrosó las filas del conservatismo. 
Martínez Camargo en 1869, descollaron en política a la vuelta del siglo XX más por sus condiciones de empresarios que de profesionales de la misma que, como se anotó, se vieron precisados a hacer sus carreras públicas desde lo más bajo. Estos empresarios que por razones obvia de sus edades se habían mantenido al margen de la política durante el liberalismo radical, conjuntamente con otros de mayor edad como Bartolomé Martínez Bossio, Juan B. Aycardi, los Pombo y Gómez Pombo, incursionaron en ella bajo el amparo de la Regeneración, y a la vuelta de siglo algunos de sus descendientes desempeñaron altos cargos en el gobierno central, entre ellos ministerios. En parte ello se debió a que el Estado, con su intervención creciente en los asuntos económicos se convirtió en punto de obligatoria reflexión y de control para acceder a algunos factores de enriquecimiento como era el remate de rentas públicas, en especial las de degüello, salinas y aguardiente.

Estos hechos generacionales son claves para entender un poco los cambios que se produjeron en la política conservadora regional a comienzos del siglo XX, pues ya la vieja guardia conservadora, de la que sólo sobrevivían M. Dávila F., G. E. O'Byrne, M. Pájaro, L. Segovia y L. Patrón R., mostraba claros síntomas de agotamiento y de rezagamiento ante la nueva mentalidad pragmática que vino con el siglo XX, siendo relevada por jóvenes nacidos en los años de 1860 y 1870, con la peculiaridad de que ahora, muchos de los prohombres del conservatismo no eran oriundos de Cartagena sino de las sabanas y de las comarcas del Sinú.

\section{LA CONTIENDA ELECTORAL DE 1904: UNA PRUEBA DE FUEGO PARA LOS SECTORES DEL CONSERVATISMO}

Mientras vivió Núñez el Partido Nacional se mantuvo monolítico en Bolívar. La presencia de su figura era algo omnipresente en la región y casi se le consultaba todo, hasta tal punto que la vida de muchos sectores sociales de Cartagena parecía girar en torno al solitario de El Cabrero, para lo que basta leer los relatos de Julio H. Palacio, Daniel Lemaitre, Juan 
Coronel o de Alfonso Romero A. para percatarse de ello ${ }^{20}$. Ya en 1890, cuando los conservadores antioqueños comenzaron a oponerse a la candidatura de Caro a la vicepresidencia, lanzando la candidatura de Marceliano Vélez, algunos conservadores cartageneros simpatizaron con esta última, pero con escaso peso dentro de ese partido. Después de su muerte (1894), algunos conservadores cartageneros hicieron eco de las divisiones nacionales, las que se acentuaron en 1897 en torno al debate por la presidencia con las candidaturas de Rafael Reyes y Miguel A. Caro, en ese momento presidente, quien silenció por la fuerza las voces de oposición en el Congreso que exigían libertad de prensa y normalidad constitucional con la abolición de la ley de los Caballos. Estos y otros hechos fueron engrosando las filas del conservatismo histórico con Marceliano Vélez, Pedro Nel, Tulio y Mariano Ospina Vásquez, Carlos E. Restrepo, Jaime Córdoba, Eduardo Posada, Jorge Roa, Guillermo Quintero Calderón, José V Concha, Miguel Abadía Méndez, Próspero Pinzón y otras personalidades ${ }^{21}$.

En Bolívar los amagos de división venían desde 1895, y al parecer eran encabezados por H. L. Román, cuñado de R. Núñez, a quien al parecer Caro profesaba cierta malquerencia por motivos de la fundación de una sucursal del Banco Nacional en Cartagena (o de un banco formado por empresarios cartageneros al que aquel prestaría dinero a bajo interés y otorgaría monopolio), propuesta encabezada por Pedro Vélez Racero, como lo manifiesta Caro en sus cartas a Núñez fechadas en febrero de 1893. A comienzos de 1895 Nicanor Insignares Sierra, hombre de confianza de M. A. Caro en Barranquilla y encargado para que conciliara los grupos en que amenazaba dividirse ese partido por motivos de la candidatura del antioqueño Marceliano Vélez, informaba que había logrado la unidad en Cartagena y que allí el velismo había dejado de existir, haciendo referencia

20 LEMAITRE, Daniel. Soledad Román de Núñez. Cartagena, Tip. Mogollón, 1938, ROMERO A., Alfonso. Historia de la Regeneración (1925), en: Ayer, hoy y mañana del liberalismo colombiano. Bogotá, ed. Iqueima, 1947; CORONEL, Juan. Un peregrino. Cartagena, Dirección de Extensión Cultural de Bolívar, 1944 ( $1^{\text {a }}$ ed: Guatemala, 1894); PALACIO, Julio H. Núnez Recuerdos y memorias (1893-1894). Barranquilla, Tip. Mogollón, 1953.

21 RODRÍGUEZ PIÑERES, Eduardo. Diez años de política liberal, 1892-1902. Bogotá, Ed. Incunables, 1985, pp. 39-40. (la ed.: 1945). 
a personajes de Barranquilla como los Carbonell, Roncallo, Martínez, Ujueta y otros.

La división debió ocurrir entre 1896 y 1898, pues en el primer año H. L. Román, juntos con quienes posteriormente militaron en el histoncismo (Juan A. Calvo y L. Segovia), firmaron un manifiesto en calidad de nacionalista. Ya para 1899 M. Dávila K, M. Pájaro H., Manuel C. Bello, José L. Calvo, H. L. Román, Pedro R. Castro, Juan B. Aycardi, Ricardo Román, Prudencio Maza, Manuel Serrano S., Ulpiano Obando, Manuel Posada, Luis M. Vergara S, Juan A. Calvo, L. Segovia y C. Vélez D., formaban parte del conservatismo histórico, pero que unieron sus fuerzas a los nacionalistas en el poder con el fin de respaldar el gobierno de Sanclemente durante la Guerra de los Mil Días ${ }^{22}$.

En el transcurso de la guerra no hubo elecciones en el país, hasta marzo de 1903 cuando se volvió a la normalidad de las contiendas pacíficas a los partidos, verificándose elecciones para escoger diputados y senadores. Estas elecciones se convirtieron I un llamamiento a cerrar filas dentro del partido conservador, a la vez que un ejercicio de lo que sería, pocos meses después la confrontación de fuerzas dentro del conservatismo en las elecciones presidenciales de 1904. En el transcurso de ambos certámenes electorales el partido liberal estuvo totalmente marginado, pues su derrota en la guerra lo había dejado sin fuerzas para afrontar cualquier debate electoral.

Con el fin de comprender el desarrollo de la política local alrededor de las elecciones, es pertinente recordar que la constitución de 1886 estableció ciertas restricciones de los canales de ex presión democrática al limitar el sufragio a los sectores populares de la población, siendo universal el voto para los varones sólo para la elección de Consejeros Municipales y Diputados a las Asambleas Departamentales. También se implantó un

\footnotetext{
22 "La patriótica actitud del Directorio Conservador llevó a formar en las filas del Gobierno a los pocos conservadores que, en esta ciudad, aún permanecían prescindentes por viejas suceptibilidades, y ya hoy todas las fracciones de ese partido forman una sola masa...". Manifiesto de los conservadores respaldando al gobierno, en: El Porvenir. Cartagena, octubre 25 de 1899. Ver: Ordenanzas y resoluciones expedidas por la Asamblea Departamental de Bolívar en sus sesiones ordinarias y extraordinarias de 1896. Cartagena, Tip. de A. Araújo, 1897.
} 
sistema indirecto de elecciones para congreso y presidencia, en el que participaban solo los ciudadanos "que sepan leer o escribir o tengan una renta anual de quinientos pesos o propiedad inmueble de mil quinientos votarán para electores y elegirán directamente representante"23. Estos electores elegían Presidente y Vicepresidente de la República. Los senadores eran elegidos por las Asambleas Departamentales, no pudiendo recaer la elección en miembros de ésta. Para elegir Representantes, "cada departamento se dividirá en tantos distritos electorales cuantos le correspondan para que cada uno de estos elija un representante". El presidente nombraba a los gobernadores y éstos a su vez a los alcaldes ${ }^{24}$.

Para las jornadas electorales que se avecinaban en el país, el partido conservador de Bolívar buscó la unión de sus dos fracciones (nacionalismo e historicismo), en esta unión se observa, una nueva orientación hacia el partido opositor, al reconocerle al liberalismo sus derechos políticos de participación en las corporaciones municipales, departamentales y nacionales. Se alude a la importancia y la necesidad de la censura del contrario como un llamado a hacer una "política grande".

Este consejo se reunió con el siguiente personal: Carlos Vélez D., Luis Patrón R. (vicepresidente), Manuel Dávila Flórez (Presidente), Manuel Castro Viola y Luis Vélez R. El día de la instalación hizo el consejo el nombramiento de las juntas electorales del departamento, resultando conformada por Cartagena de la siguiente forma: Juan A. Calvo, Manuel Pájaro H. y Gabriel Jiménez, principales; Antonio R. Blanco (liberal), Julio Benedetti y Fulgencio Lequerica ${ }^{25}$.

Para el período presidencial de 1904 a 1910 sonaban varias combinaciones, y todavía el partido conservador no se había decido por alguna de estas combinaciones. Después de muchas deliberaciones en el seno del partido conservador, la opinión se dividió mayoritariamente alrededor de los nombres de Joaquín F. Vélez y Rafael Reyes.

${ }^{23}$ URIBE VARGAS, Diego. Las Constituciones de Colombia Ediciones Cultura Hispánica. Madrid. 1977. T II, p. 1.004.

24 Ibid.

25 El Porvenir. Cartagena, enero 14 de 1903. 
Pues bien, escogidos los dos candidatos la unión del conservatismo bolivarense llevada a cabo desde los inicios de la guerra entró en crisis. En efecto, las candidaturas de Rafael Reyes y del cartagenero Joaquín F. Vélez, terminaron fraccionando a este partido en Bolívar, llamando la atención que el grueso de sus dirigentes más sobresaliente haya optado por respaldar la candidatura del primero, si se tiene en cuenta que Vélez era cartagenero, y se le reconocía una moralidad a toda prueba y capacidades administrativas demostradas en varias oportunidades al frente de la gestión pública bolivarense. Además, él fue quien reorganizó en el año de 1866 el conservatismo de esta región y poseía alguna ascendencia sobre estratos populares como era el caso de los habitantes del barrio Chambacú, parte del actual barrio de Getsemaní.

Todo lo que se pueda decir sobre las adscripciones a estas candidaturas son conjeturas mientras no se tenga a la mano la correspondencia de estos personajes. Con relación a J. F. Vélez existía mucho resentimiento, pues además de su proceder rígido en el manejo del poder en los períodos en que estuvo al frente de la gobernación de Bolívar, también sucedió que, como señala un historiador liberal de la época, se le había maltratado su imagen al considerársele como un apaga-incendios en los momentos de guerra (1895 y 1899-1902), cuando se le traía de Roma para colocarlo al frente de la Jefatura civil y militar de Bolívar, teniendo que aplicar medidas de excepción que generaban animosidades ${ }^{26}$. También existían resentimientos personales y familiares como fue el caso del llamado "círculo Román", sobre el que escribiera Nicanor Insignares a M. A. Caro, grupo que mientras vivió Núñez había logrado fortalecer sus posiciones en la administración pública departamental. En 1889 la parentela de los Román controlaba cuatro importantes cargos en la Aduana de Cartagena, cinco en la administración departamental de Bolívar, cinco en la Aduana de Barranquilla, dos en la administración departamental de Panamá, y seis en la representación nacional en el exterior ${ }^{27}$. Pues bien, una vez muerto

26 RODRÍGUEZ PIÑERES, Eduardo. Diez años de Política Liberal 1892-1902. Bogotá, Ed. Incunables, 1985 , pp. 56-57.

27 Ver: El Precursor. Bogotá, Noviembre $1^{\circ}$ de 1889. Citado por: AGUILERA P, Mario. La Insurgencia Urbana en Bogotá. Santafé de Bogotá, Eds. Colcultura, 1997, pp. 445-446. 
Núñez, J. F. Vélez se convirtió en el prohombre de la política bolivarense, y en sus diversas administraciones al frente de los destinos públicos del departamento fue desmontando esa de nepotismo. Otra razón del respaldo de algunos familiares de J. F. Vélez a la candidatura de Reyes fue algunas desavenencias familiares con los Vélez Daníes sobre la que poco conocemos $^{28}$.

Sin embargo y sobre todos estos factores, el escaso apoyo a Vélez lo que denota es el enfrentamiento al interior del conservatismo de dos maneras de concebir las nuevas realidades que vinieron después de la Guerra de los Tres Años y con el nuevo siglo, y por tanto, puntos de vista disímiles acerca de las relaciones con el liberalismo y del manejo del poder. Un ligero conocimiento de los personajes que respaldaron las mencionadas candidaturas permite extraer algunas conclusiones. Entre quienes apoyaron a Vélez sobresalen viejos militantes del conservatismo, políticos de carrera con escasos vínculos con las actividades empresariales. Lácides Segovia (político de carrera), Manuel Pájaro H. (médico y político de carrera), Amaranto Jaspe (pequeño empresario), José Ulises Osono (abogado y político de carrera), Francisco Cruz, Ramón P. de Hoyos (abogado), Henrique A. de la Vega (médico), M. Dávila F. (abogado y político de carrera), Pedro y Luis Vélez Racero (empresarios), José María de la Vega (empresario), Luis Felipe Jaspe (pequeño empresario y maestro de obra), A. J. de Insarri (educador). En el área del Sinú los Cabrales, Burgos R., Vellojín Burgos, Gómez Pérez y otros hacendados apoyaban a Vélez. Con excepción de H. de la Vega, José U. Osorio y M. Pájaro, todos estos personajes se habían educado bajo la dirección de J F. Vélez y Abel M. Irisarri en el Colegio de La Esperanza, siendo algunos de ellos reconocidos por su doctrinarismo y por hacer de la doctrina católica la línea de división con relación al liberalismo.

La candidatura de Reyes fue respaldada por Pablo J. Bustillo (abogado), Fernando A. Gómez Pérez (empresario), Juan A. Calvo, Milcíades Rodríguez (militar), Pedro J. Cabarcas, Camilo S. Delgado (médico), 
Miguel Rodríguez, Marcial González, Gabriel Eduardo O'Byrne (periodista), Fanor Vélez, Gabriel Jiménez M., Agustín Gari (artesano), Luis Patrón Rosano (hacendado, educador y político), José María Pasos (propietario de gran cantidad de bienes inmuebles urbanos), Dionisio Jiménez (empresario), Bartolomé Martínez Bossio (empresario), José María Berástegui (hacendado), Gerómmo Martínez A. (empresario), J. A. Gómez Recuero (empresario), Diego Martínez C. (empresario), Juan Gastelbondo (médico), Carlos y Fernando Vélez D. (empresarios), H. L. Román (empresario), Luis E. Calvo, Claudio A. Royo y Joaquín Escandón ${ }^{29}$.

Muchos de éstos habían conocido a Reyes durante las guerras civiles de 1885 y 1895, y habían respaldado su candidatura a la presidencia en 1897; además, Reyes no estuvo presente durante la Guerra de los Mil Días, la que continuaba polarizando los ánimos partidistas. Les atraía su pragmatismo político, a la vez que le reconocían el atributo de haber permanecido por encima de muchos de los conflictos políticos y civiles, como también su no adscripción en ninguno de los dos sectores en que se hallaba dividido el conservatismo $^{30}$. Los resultados de las elecciones en algunas provincias del departamento de Bolívar fueron las siguientes:

\footnotetext{
${ }^{29}$ El Porvenir. Cartagena. Septiembre 9 de 1903.

30 Sobre este último punto ver: LEMAITRE, Eduardo. Rafael Reyes. Biografía de un gran colombiano. Bogotá, Banco de la República, 1981, p. 177.
} 
TABLA 1

RESULTADO DE LOS VOTOS DE LAS ASAMBLEAS
ELECTORALES EN BOLIVAR

\begin{tabular}{ccccc}
\hline Provincias & Reyes & Vélez & Esguerra & J.F.Insignares \\
\hline CARTAGENA & 21 & 16 & 8 & \\
ELCARMEN & 22 & 12 & & \\
MOMPOX & 21 & 1 & & 9 \\
BARRANQUILA & 38 & 10 & & \\
LORICA & 32 & 6 & & \\
SINCELEJOY & & & & \\
COROZAL & 37 & 1 &
\end{tabular}

Desde antes de la subida de Reyes al poder, los seguidores de J. F. Vélez fueron barridos de la administración pública. A comienzos de 1903 era gobernador el general velista Luis Vélez Racero, sobrino del candidato; finalizando ese año el presidente J. Marroquín nombró gobernador a Insignares Sierra, seguidor de Reyes quien procedió a colocar en los cargos más importantes de la administración departamental a personas adictas a su candidato $^{32}$.

A nivel departamental José Francisco Insignares, Gobernador por ese entonces de Bolívar, se encargó de abrir el campo para el triunfo de Reyes, para esto, se trasladó el despacho de la gobernación fuera de la capital, para así conseguir apoyo favorable en las provincias del departamento.

La oposición a la candidatura de Vélez por el sector nacionalista, al parecer mayoritario en el departamento de Bolívar, incluía también las aspiraciones por un cambio de actitud política, al buscar dejar atrás las costumbres existentes, la intransigencia política, las ideas basadas en los recios principios de la filosofía católica y espiritualista, el autoritarismo,

31 El Porvenir. Cartagena, 7 y 10 de Febrero de 1904; BURGOS R, R. Op. Cit, p. 113. Además, en Cartagena Nicolás Esguerra sacó 8 votos (liberales) y Carlos Vélez D. 1. En Sabanalarga Vélez triunfó por unanimidad. Los votos de Insignares S los colocaron los liberales de Barranquilla (F. de P. Manotas, Clemente Salazar M., Demetrio Dávila, Urbano Pumarejo, José Martínez Salcedo, A. M. Lafaurie, Celso Solano Manotas, José M. Crespo C. y Manuel Z. de la Espriella).

32 Ver: Lista de las personas que no pueden ser elegidos Representantes ni Diputados..., en: Registro de Bolivar. Cartagena, abril 15 de 1904. La citada biografía sobre el General Burgos está llena de denuncias sobre las maniobras políticas de Insignares a favor de Reyes. 
características que se le atribuían a Vélez, por lo que era criticado, incluso por sus mismos familiares quienes le negaron su apoyo ${ }^{33}$.

A pesar de la polémica que suscitó el triunfo del General Reyes, imperaba en el país un gran anhelo por la reorganización, impuesto por las amargas experiencias recientes. Desde un principio se observó el afán de Reyes por apartarse de la tradición exclusivista de los partidos políticos, nombrando en su gabinete a individuos de ambos partidos, dando una orientación económica a su política, donde su preocupación, como asegura Humberto Vélez, fue más en el camino de la administración que de la política, haciendo sentir la presencia de nuevas fuerzas sociales (industriales y terratenientes modernizantes) en las nuevas políticas de estado ${ }^{34}$. Sus lemas de gobierno "paz y concordia" y "menos política y más administración" fueron las piedras de inicio, lo primero que se debería lograr para llevar al país por el camino tan anhelado del estado moderno; un estado fortalecido económicamente.

Reyes dio un gran estímulo a la industria, como consecuencia se impulsó el modelo del "hombre práctico", símbolo que "se multiplicó en todas las regiones en la imagen del empresario, el que comenzó a aparecer y a ser mostrado como un hombre de cualidades especiales" ${ }^{\text {"35. También es }}$ importante tener en cuenta, el fortalecimiento del ritmo urbano de la política, apartándose de las tradicionales redes de poder militar-caudillista por una organización más partidista y burocrática, el llamado a un debate civilizado, apartado de las contiendas armadas como único modo de resolver las diferencias doctrinales. El crecimiento urbano y económico de la ciudad condujo a trasladar el debate político del aspecto ideológico a lo práctico. La preocupación recurrente por la administración pública, el afán por la modernización de la ciudad para colocarla al nivel de otras ciudades del mundo o por lo menos dotarla de los servicios mínimos de que gozan las ciudades de cara al nuevo siglo, servicios públicos adecuados, la

33 AGUILERA. Op. Cit., p. 96.

34 VELEZ, Humberto. "Rafael Reyes: Quinquenio, Régimen Político y Capitalismo (1904-1909)". Nueva Historia de Colombia. Ed. Planeta. Bogotá, 1985.

35 SOLANO. Op. Cit., p. 68. 
construcción de amplias calles, plazas, camellones que brindaran comodidad y esparcimiento, la conformación de clubes sociales; en otros términos, el interés por la ciudad se constituyó en una obsesión ${ }^{36}$. Es en este terreno donde se fue centrando el debate político de la época, y en este espacio, la figura del empresario y el administrador entraron, como ya se anotó, a representar un papel clave en las nuevas relaciones políticas de la ciudad y a organizarse otra forma de clientela a través de redes burocráticas.

36 Ibid., p. 67. 